Journal of Chromatography A 1186 (2008) 51-66

Publisher: ELSEVIER SCIENCE BV, PO BOX 211, 1000 AE AMSTERDAM, NETHERLANDS

Subject Category: Biochemical Research Methods; Chemistry, Analytical

ISSN: 0021-9673

DOI: 10.1016/j.chroma.2007.10.017

http://www.sciencedirect.com/science? ob=ArticleURL\& udi=B6TG8-4PW5XKX-

B\& user $=2347467 \&$ coverDate=04\%2F04\%2F2008\& alid=1140654144\& rdoc=7\& fmt=high\& orig=search\& cdi=5248\& sort= r\&_docanchor $=\&$ view $=c \&$ ct $=23 \&$ acct $=C 000057013 \&$ _version $=1 \&$ _urlVersion=0\&_userid $=2347467 \&$ md5 $=$

$11 \mathrm{ac} 917792 \mathrm{a} 9 \mathrm{fc} 539 \mathrm{aa38c} 5 \mathrm{~d} 1263 \mathrm{~b} 4 \mathrm{~d} 1$

Review

\title{
Recent trends and developments in pyrolysis-gas chromatography
}

Karina L. Sobeih, Mark Baron*, Jose Gonzalez-Rodriguez

Department of Forensic and Biomedical Sciences, University of Lincoln, Brayford Pool, Lincoln LN6 7TS, UK

*Tel: +44 (0) 1522 886879, Fax: +44 (0) 1522 886791, email: mbaron@lincoln.ac.uk

\begin{abstract}
Pyrolysis-gas chromatography (Py-GC) has become well established as a simple, quick and reliable analytical technique for a range of applications including the analysis of polymeric materials. Recent developments in Py-GC technology and instrumentation include laser pyrolysis and non-discriminating pyrolysis. Progress has also been made in the detection of low level polymer additives with the use of novel Py-GC devices. Furthermore, it has been predicted that future advances in separation technology such as the use of comprehensive two-dimensional gas chromatography will further enhance the analytical scope of Py-GC.
\end{abstract}

Keywords: Pyrolysis; GC; Polymers; Laser pyrolysis; Non-discriminating pyrolysis; Polymer additives

\section{Contents}

1. Introduction

2. Pyrolysis-GC technique

2.1 Instrumental configuration

2.1.1 Types of pyrolyzers

2.1.2 Importance of pyrolysis-GC interface

2.1.3 Types of detectors

2.2 Sample preparation

2.2.1 Derivatization

2.3 Instrumental developments

2.3.1 Laser pyrolysis-GC

2.3.2 Non-discriminating pyrolysis-GC

3. Thermal degradation

3.1 Degradation properties

3.2 Mechanisms

4. Applications 
Journal of Chromatography A 1186 (2008) 51-66

4.1 Art materials

4.2 Biological samples

4.3 Environmental

4.4 Food and agriculture

4.5 Geochemistry and fuel sources

4.6 Synthetic polymers

4.6.1 Detection of additives and contaminants

\subsection{Forensic}

5. Miscellaneous

6. Conclusion

7. Acknowledgments

8. References

\section{Introduction}

Pyrolysis has been used extensively over the last 20 to 30 years as an analytical technique in which large molecules are degraded into smaller volatiles species using only thermal energy. The ultimate objective of analytical pyrolysis is to use the chromatographic information of pyrolysis products to determine the composition or structure of the original sample. The complexity of polymeric materials can vary extensively and they can be very challenging to analyse. Pyrolysis, combined with modern analytical methods, such as gas chromatography and/or mass spectrometry (Py-GC/MS) has become a quick, convenient and powerful tool for characterising polymers from involatile, complex heterogeneous samples. Previous reviews on Py-GC instrumentation, methods and applications were published by Wampler [1] and Wang [2] in 1999 and Moldoveanu [3] in 2001. Since this time there have been major instrumental developments in laser pyrolysis systems and non-discriminating pyrolysis techniques as well as progress in the use of Py-GC for the detection of low level additives in polymers. This review mainly covers the period from 1999 to 2007 but also included are references to literature before this period that appear not to have been covered in previous reviews.

\section{Pyrolysis-GC technique}

\subsection{Instrumental configuration}

The standard configuration of a pyrolysis-GC instrument has been discussed previously and largely remains the same in that the pyrolysis device, or pyrolyzer, is interfaced with the analytical column of the GC via the injection port [2]. A flow of inert gas, such as nitrogen or helium, flushes the pyrolyzates into the column, where components are separated. As discussed by Wampler, capillary columns offer the advantage over packed columns of higher resolution [1]. The detection method used is typically mass spectrometry but other GC detectors have also been employed depending on the intentions of the analysis. Nevertheless, instrument configuration is often varied. Newly developed thermal analysis equipment designed to enhance performance may replace existing ones or be incorporated in order to meet specific applications. Such developments include the use of lasers as a fragmentation source and more recently a technique called in-column or non-discriminating pyrolysis, all of which are discussed in detail below. This constant refinement of instrumental devices and parameters during the past 20 years provides an expansive record on the pyrolysis of polymers. 
Journal of Chromatography A 1186 (2008) 51-66

\subsubsection{Types of pyrolyzers}

The three most commonly used and recognised pyrolyzers for GC are the microfurnace, Curie-point and resistively heated filament $[1-2,4-6]$.

The microfurnace rapidly raises the temperature of the sample until the pyrolysis temperature is reached and then maintains this temperature for the desired pyrolysis time. The samples are either injected or dropped into the pyrolysis zone by liquid syringe, solid plunger syringe or by using a small cup. The desired characteristics of this type of pyrolyzer, such as reproducibility, have always been difficult to develop [4]. Although much improved, most available furnaces still suffer from the relative drawback of rise times of several seconds [7]. Tsuge et al. developed a multifunctional microfurnace pyrolyzer for pyrolysis-GC and evolved gas analysis of various synthetic and natural materials $[5,8]$. The system was composed of a double shot microfurnace pyrolyzer with a sophisticated temperaturecontrol device; a GC equipped with an ultrahigh-temperature metal, chemically inert capillary separation column; and a quadrupole MS with an electron impact (EI) and/or chemical ionization (CI) source. It proved to be a very effective tool for a wider range of applications including, the structural characterisation of copolymer-type polycarbonates (PCs), the determination of flame-retardant mechanisms of PC, trace determination of stabilizers, the rapid characterisation of natural products, and forensic identification of various drugs and oils.

Curie-point pyrolyzers accurately reproduce pyrolysis conditions using ferromagnetic metals. The sample, which is positioned on to the end of a pyrolysis wire made from an appropriate ferromagnetic alloy, is inserted into the pyrolyzer and rapidly heated using a high frequency induction coil. The temperature ceases to rise when the Curie-point of the metal has been reached; that is the exact reproducible temperature at which the ferromagnetic material loses its magnetism. At this point the temperature remains constant until the coil is switched off [7]. In contrast to the microfurnace, the rise time of Curie-point pyrolyzers is much quicker from 0.2 to 0.4 seconds. However, the choice of different pyrolysis temperatures is limited since they are determined by the Curie-points of available materials [9]. Buco et al. used Curie-point Py-GC/MS for the determination of polyaromatic hydrocarbons (PAHs) in contaminated soil [10]. The technique proved particularly effective for lowmolecular-mass PAHs but lacked in sensitivity for quantification of high-molecular-mass PAHs. It demanded a short operating time and required no extraction solvent. In addition, the results showed good accuracy for the measured PAHs when compared with a certified soil.

Filament pyrolyzers can acquire a controlled pyrolysis temperature extremely quickly by using a piece of resistive metal. An initial pulse of heating at a high voltage produces a current through the metal causing the filament to heat rapidly until the programmed pyrolysis temperature is reached. The pyrolysis temperature is maintained by reducing the voltage. Various commercial models of the Pyroprobe appear to be the most widely used filament pyrolyzer. Samples that are soluble in a volatile solvent are pyrolysed using a ribbon probe, those that are not are heated using a coil probe [4]. Whilst samples are added directly onto the ribbon probe, quartz tubes are used to hold the samples before being inserted into the coil probe. With regards to the latter, the exact pyrolysis reaction time is difficult to determine since the sample never comes into direct contact with the filament [9]. Reproducibility with this system is very good providing that care is taken to ensure consistency with sample size and positioning [4,11].

Heated filament and Curie-point pyrolysis result in less secondary pyrolysis products compared to furnace pyrolysis and thus, the resulting pyrograms are easier to interpret. A major disadvantage exists with all three conventional pyrolyzers in that because they are mounted external to the GC system, they are prone to the deposition of higher-boiling point pyrolyzates and condensation of reaction products in the transfer line. This often results in sample losses and discrimination of high-molecular weight components $[9,12]$. 
Journal of Chromatography A 1186 (2008) 51-66

\subsubsection{Importance of pyrolysis-GC interface}

The rapid and efficient transfer of pyrolysis products from the pyrolysis zone to the GC column is vital in order to attain good peak resolution. The interfacing of these two devices is therefore very important. Several parameters for the pyrolyzer have been identified in order to achieve this [1]. The pyrolyzer needs to heat the sample as instantaneously as possible to prevent drawn out transfer of the pyrolyzates through the injection port. It also needs to have a small internal volume and a rapid carrier flow to make sure all of the volatiles are swept out and onto the column and are not left in the hot zone to undergo secondary pyrolysis. Finally, a small sample size is essential to ensure that all of it degrades rapidly, and that the column capacity is not exceeded. At too large a sample size, parts of the sample may pyrolyze before others affecting reproducibility. As a result of these operating conditions, interfacing between the pyrolyzer and the GC injection port should be kept minimal to reduce the surface area and volume through which the pyrolyzate compounds travel. It should also be kept hot and insulated to eliminate cold spots and prevent condensation reactions.

The above conditions are not always attainable or suitable for particular experiments and variations always occur. For example, lower temperatures are often used to study the degradation kinetics of a material i.e. its thermal stability and degradation mechanisms.

\subsubsection{Types of detectors}

The purpose of a detector used in conjunction with pyrolysis-GC is to monitor the carrier gas as it leaves the column and respond to changes in its composition as solutes are eluted. Ideally a detector should show a rapid response time, a wide range of linear response and high sensitivity. Mass Spectrometry continues to be the most widely used detector in qualitative and quantitative polymer analysis. The main advantage with MS is that it preserves the complex patterns of the initial sample by means of a mass spectrum corresponding to each peak in the GC profile, therefore allowing for the characterisation of polymers, the identification of additives and contaminants in polymeric samples and the determination of degradation mechanisms. The different methods of sample ionization available for MS allow for different degrees of fragmentation of the sample. Electron impact ionization involves the bombardment of sample molecules with high energy electrons and is the usual choice for the identification and structural analysis of complex macromolecules because it results in a higher degree of dissociation. Chemical ionization has also been used in polymer analysis for much gentler, more selective ionization whereby much less dissociation into ions of smaller mass occurs. Recently an alternative selective ionization method, metastable atom bombardment, has been reported [13-15] allowing the direct and fast insertion of samples into the mass spectrometer reducing analysis time. Quadrupole MS analysers, in particular, offer different modes by which mass spectra can be acquired depending on the purpose of the investigation. Selected ion monitoring (SIM) compared to total ion monitoring is a much more sensitive scanning mode for target compound identification. Instead of completing full scans of the chromatogram and collecting all of the ion fragments, SIM only measures and records pre-selected ions for a given retention time window. Thus if fragments were created at $\mathrm{m} / \mathrm{z}$ values other than those selected, data regarding those ions would not be recorded. SIM requires the retention data of compounds to perform a scan and in the case of co-eluting pyrolysis products; it is not able to distinguish between two compounds with the same mass ions and retention time.

Magnetic, quadrupole, ion trap and time-of-flight mass spectrometers have all been successfully coupled to conventional Py-GC instruments. The rapid analysis of polymers has specifically been achieved using time-of-flight mass spectrometry (TOF-MS) [11,13]. TOF-MS can acquire highdensity data across narrow GC peaks and has proven to be a suitable detection system for fast GC 
separations without compromising the chromatographic peak information. There is an extensive amount of literature available on the use of Py-GC/MS for a wide range of applications, some of which will be mentioned throughout this review and some of which have been reviewed in a recent paper by Peacock and McEwen [16].

Isotope-ratio mass spectrometry (IRMS) has also been successfully combined with Py-GC. IRMS allows for the highly precise analysis of the stable-isotopic composition of organic compounds separated by GC. All IRMS instruments work in EI mode, use a single magnetic-sector analyzer, and multiple Faraday detectors for analog measurement of ion currents. A more detailed overview and evaluation of IRMS is provided in a recent paper by Sessions [17]. Although not yet a widely used technique, Py-GC/IRMS has proven to be useful for some applications. Pel et al. performed cytometric cell sorting and compound-specific Py-GC/IRMS analysis to determine population-specific isotopic signatures and growth rates in cyanobacteria-dominated lake plankton [18]. They reported that PyGC/IRMS was able to analyse very small samples and reduced the chances of contamination and sample loss during handling. Impressed with the resolution achieved, they also recognized the potential of Py-GC/IRMS in the future analysis of plankton dynamics. A similar study used PyGC/IRMS to determine planktonic community structure and trophic interactions and further recommended the technique for carbon isotope-based food web studies [19]. In a more unusual study, Py-GC/IRMS was used to obtain isotopic and structural information from the macromolecular material in meteorites [20]. The results highlighted the ability of the technique to analyse milligram-sized samples without compromising the resolution. Gleixner et al. studied the individual turnover rate of specific carbohydrates, lignin, lipids and N-containing compounds from French arable soil using Curiepoint Py-GC/IRMS [21]. Again its potential as a technique to analyse organic compounds was highlighted.

Differential mobility spectrometry (DMS) [22] and ion mobility spectrometry (IMS) [23-25] are recognized methods for the detection of chemical and biological agents (gases, vapors and aerosols) in field settings. As advanced portable instruments they are small, highly sensitive, require little power and are capable of fast analysis times. Py-GC/IMS has proved particularly useful for the detection and identification of certain degradation compounds resulting from the pyrolysis of biological material, such as bacterial spores which could be used as biological warfare agents. Open and closed sample introduction tubes have been used in the Py-GC/IMS system for the detection of biological aerosol particulates and chemical compounds in water respectively. A study in 2001 made improvements to an existing Py-GC/IMS system in order to increase the amount of pyrolyzate compound information reaching the IMS detector [23]. The airflow enhancement through the pyrolysis tube allowed for an increase in the previously observed biomarkers for aerosols. The altered Py-GC/IMS instrument was subjected to several outdoor aerosol trials in which it was shown to provide information regarding the biological or non-biological nature of an aerosol and more specifically discriminate between aerosols of a gram-positive spore, a gram-negative bacterium, and a protein. Yinon provides a comprehensive review on instrumental advances and developments in IMS and further assesses its ability as a fast, general analytical measurement device [24]. A recent study compared both open tube and closed tube sample introduction Py-GC/IMS systems for the analysis of water contaminated with a surrogate chemical warfare agent [25]. Results showed that the limit of detection for the VX nerve agent surrogate was lowered by two orders of magnitude for the closed injector compared to the open tube system, making the closed tube Py-GC/IMS system more suitable for detecting chemicals in liquids.

Besides MS [26-30] and mobility spectrometers, other Py-GC detection methods have been reported for a wide variety of applications. These include, flame ionization detection (FID) [31-36] and atomic emission detection (AED) [37-40].

\subsection{Sample preparation}


Journal of Chromatography A 1186 (2008) 51-66

Often, time consuming pre-treatments of the sample are required to make it amenable for Py-GC/MS analysis. Depending on the nature of the sample, this can involve a simple hydrolysis or dissolution step and/or a more complex derivatization process.

\subsubsection{Derivatization}

Derivatization involves the conversion of non-volatile polar or thermally sensitive compounds into related more volatile derivatives. It is a well established technique in pyrolysis-GC, extending the capabilities of pyrolyzate analysis by improving the behaviour of the analyte during separation in the column, modifying the thermal degradation pathway or enhancing detectability of the analyte. Different methods of derivatization have been reported, namely hydrogenation, methylation and silylation, whereby the hydroxyl, carboxyl and amino functional groups in polar compounds are converted into much less polar methyl, trimethyl or trifluoroacetyl derivatives of greater volatility using appropriate reagents. The most commonly used derivatising reagent is tetramethylammonium hydroxide (TMAH) although other quaternary ammonium hydroxides have also been reported as effective reagents. Haffenden and co-workers developed a novel Py-GC/MS based methodology to analyse the composition of non-volatile residues of Maillard reaction products in two separate studies [41,42]. Both studies involved a post-pyrolytic in-situ derivatization technique, the first using hexamethyldisilazane (HMDS) and the second using trimethylsilyldiethylamine as silylating reagents. The application of the technique indicated the formation of several derivatives in both cases. The analytical characterisation of diterpenoid and acrylic resins employed in art works has been achieved using an on-line derivatization method using HMDS reagent and Py-GC/MS [43,44]. Results obtained were compared with previously reported results from in-situ thermally assisted hydrolysis and methylation with TMAH. Several non-reported trimethylsilylated derivatives of compounds present in the diterpenoid resins were identified. In both cases, improved sensitivity, better resolution of the most representative peaks and more simplified, well-resolved chromatograms were obtained by using HMDS as a derivatizing reagent.

Thermally assisted hydrolysis and methylation (THM) is an alternative on-line derivatization technique for Py-GC/MS, which is much simpler and faster compared to wet chemically derivatization methods. Asperger and co-workers analysed natural waxes using THM in the presence of TMAH, carried out on a filament pyrolyzer $[45,46]$. They found THM to be a very suitable derivatization method which was able to overcome problems such as the generation of non-specific pyrolyzates observed in conventional Py-GC analysis of waxes. The method enabled both rapid fingerprinting and detailed compositional analysis by means of structural elucidation of the THM products. The effect of TMAH used in THM, in comparison with the effect of sodium hydroxide on the slow pyrolysis of cotton cellulose has been reported [47]. Information regarding the reactive decomposition of cellulose was obtained using Py-GC/MS. In a recent study, Ikeya et al. compared an off-line methylation method using carbanion and methyl iodide reagent with thermally assisted hydrolysis and methylation using TMAH on Py-GC analysis of humic and fulvic acids [48]. The off-line methylation proved to be the better method as it produced additional information on structural unit of humic substances.

There are a number of excellent reviews available on derivatization methods. Wang discussed both pre and post-derivatization techniques adapted for Py-GC analysis [2]. Particular focus was placed on the developments in pre-pyrolysis derivatization, which is used to convert the functional group in the polymer to obtain a favourable degradation pathway during pyrolysis. A review on Py-GC/MS by Moldoveanu in 2001 reported advancements in derivatization techniques including methylation and silylation [3]. The same year, a review by Challinor on the development and applications of on-line and off-line thermally assisted hydrolysis and methylation reactions in analytical pyrolysis was 
Journal of Chromatography A 1186 (2008) 51-66

published [49]. Trimethylsulphonium hydroxide (TMSH), tetramethylammonium acetate (TMAAc) and $\mathrm{N}, \mathrm{O}$-bis(trimethylsilyl)trifluoroacetamide (BSTFA) reagents provided more specific advantages when compared to TMAH where particular applications were required. A recent review by Halket and Zaikin published in 2006 describes on-line derivatization methods employed in mass spectrometry, including Py-GC/MS [50].

\subsection{Instrumental developments}

Gains in chromatographic sensitivity are continually being made with improved techniques and instrumentation, including the design of sophisticated gas inlet systems and interfaces which improve the efficiency of the trapping and transfer of gaseous products to the GC column. In addition, progress continues to be made with GC detectors including mass spectrometry, which also contributes to the ever increasing power of Py-GC systems. However, details regarding such improvements are beyond the scope of this review. The most significant instrumental improvements in pyrolysis-GC include laser pyrolyzers for the analysis of microscopic samples, and non-discriminating pyrolysis for the analysis of high-molecular weight pyrolysis products.

\subsubsection{Laser pyrolysis-GC}

Micro analytical techniques that facilitate the separate analysis of distinct regions within complex heterogeneous samples have an increasing application in polymer analysis. Laser pyrolysis-gas chromatography (laser Py-GC), or laser micropyrolysis-GC, is one such technique, however studies which have utilized this method are limited. Although early works involving the analytical technique and its applications date back to the early 1970s, recent studies are still primarily focussed on instrumental development. This lack of progress is due to a number of factors including i) the sensitivity limitations of existing chromatographic technologies required for testing the typically small product concentrations; ii) the inter-disciplinary skills needed; iii) the financial expense of the different instruments; iv) the difficulties involved with interfacing these instruments; v) the lack of understanding of the interactions between laser and material; and vi) the issue that not all samples are compatible with laser radiation to produce pyrolysis products [51,52].

The laser pyrolysis or micropyrolysis system (Fig. 1) consists of the laser and associated optical device; the sample chamber and cold trap; and a GC/MS for separation and detailed molecular characterisation of the pyrolysis products (i.e. molecular fingerprinting). Interfacing between the sample chamber and the cold trap inside the GC injection port has been achieved using a heated transfer tube, a sophisticated gas inlet system, or more recently using a specially designed pyrolysis valve interface which can function both on-line and off-line (CDS Analytical, model 1500). Solid polymer samples of small size are mounted in the sample chamber and then viewed through the microscope until a suitable area to be pyrolyzed is located. The laser is focussed through the microscope objective and the targeted area is pyrolyzed using either a continuous wave or a number of high-energy pulses. The size of the crater formed and thus the intensity of pyrolyzate distribution is dependent upon the degree of focussing and the time span and energy setting of the laser. During pyrolysis, a helium carrier gas sweeps the pyrolyzates from the sample cell and (ultimately) onto the cold trap via a heated transfer line. Once collected, components are desorbed onto the GC column for subsequent analysis.

The use of a laser and a microscope in place of a conventional pyrolyzer such as those mentioned earlier, facilitates visual observation of the sample and focusing of the laser beam onto a specific area and layer to achieve selective heating. This can therefore provide useful data on the molecular 


\section{Journal of Chromatography A 1186 (2008) 51-66}

compositional units of macromolecules in situ, something that traditional bulk pyrolysis methods cannot. The short duration laser beam is collimated enabling it to target the isolated components with an immense amount of thermal energy [53]. This thermal interaction between laser and material initiates a shock which in turn produces a range of pyrolysis products [11]. These extreme heating rates are characteristic of laser pyrolysis and also serve a great purpose in minimizing secondary pyrolysis reactions.

A variety of different lasers can be used as a fragmentation source depending on the type of material being pyrolysed. Greenwood et al. analysed various organic fossil samples, namely Sydney Basin torbanite, Green River oil shale and Tasmanite oil shale, to test the efficiency and potency of laser micropyrolysis-GC/MS equipped with a continuous wave Nd:YAG laser with a near IR output (1064 $\mathrm{nm})$ [51,53]. A pulsed ruby laser $(694.3 \mathrm{~nm})$ was used to study the in-situ pyrolysis of individual coal macerals [54]. Thomsen \& Egsgaard described an instrumental set-up for the pressurized laser-induced pyrolysis of coal foils using the visible blue-green emission from an argon ion laser (458-515 $\mathrm{nm}$ ) [55]. Choi et al. performed direct chemical analysis of UV laser ablation products of organic polymers using an $\mathrm{ArF}$ excimer laser $(193 \mathrm{~nm})$ coupled to a Py-GC/MS [56]. Other applications involving all of these laser sources have been briefly reviewed by Meruva and co-workers [11,52]. They themselves designed and developed a novel instrument for rapid characterisation of synthetic polymers using UV laser pyrolysis coupled to fast GC and TOF-MS. The combined Q-switched Nd:YAG laser, frequency quadrupled to $266 \mathrm{~nm}$, was used on a model polymer (polyethylene) in order to measure the production and distribution of pyrolysis products. They provide an excellent discussion evaluating the effects of experimental factors and interactions on the performance of the laser Py-GC/TOF-MS system in comparison to conventional filament pyrolysis.

Unlike the filament, Curie-point and furnace pyrolyzer, laser pyrolysis requires very little sample preparation or pre-treatment since analysis is performed directly on the solid polymer matter. The sample is therefore much easier to handle and consequently analysis time is greatly reduced. However, a common problem encountered with using laser radiation is that a specific laser wavelength may not be appropriate for all types of materials. The transparency of some polymers at the laser wavelength makes them more difficult to degrade thermally. To overcome this, researches have found that the sample can be indirectly pyrolysed by embedding it in a strongly absorbing matrix such as powdered carbon [57] or graphite, or by depositing the sample on an absorbing surface such as blue cobalt glass [58]. However, it has been reported that by heating the sample indirectly, both the heating rate and maximum temperature are decreased [59]. Armitage et al. discussed the difficulties in directly analyzing synthetic fibres using near IR laser radiation $(1064 \mathrm{~nm})$ due to their transparency at this wavelength [60]. Consequently the fibres were impregnated in a graphite matrix and then pyrolysed. They concluded that the use of additional laser sources such as UV or visible lasers may have enhanced the analytical scope of their method. Metz and co-workers reported that by using a $1064 \mathrm{~nm} \mathrm{Nd:YAG}$ laser, frequency quadrupled to $266 \mathrm{~nm}$, the addition of carbon or other sample supports could be avoided [52]. Since most organic compounds efficiently absorb UV energy, optically transparent polymers could be directly pyrolysed.

The capabilities of laser pyrolysis-GC have been assessed in many areas of research including geochemistry and petrology [61,62], natural and synthetic organic polymers $[63,64]$, and forensic science [60] (Fig. 2). Laser energy continues to be a suitable source to generate pyrolysis for the in-situ molecular investigation of macromolecules.

\subsubsection{Non-discriminating pyrolysis-GC}

Discrimination of high molecular weight compounds during the pyrolysis of complex mixtures is a significant problem with all types of conventional pyrolyzers [12, 65-67] as these fragments often carry 
very significant structural information. Efforts have been made using a laser pyrolysis system to analyse both low and high molecular pyrolyzates [52]. A technique called in-column pyrolysis (Fig. 3) established in 2000 was designed to overcome this problem by enabling the pyrolysis step to be performed in-line with the GC column [9]. Samples were introduced by hand into a disposable, inert stainless steel capillary tube, which was then heated rapidly to the pyrolysis temperature using an electric current. The entire assembly was contained within the GC oven to prevent cold spots in the system. Initial experiments demonstrated no discrimination effects of high boiling point compounds and excellent pyrolysis reproducibility. However, limitations of the in-column pyrolysis system included disconnection of the column every time a new sample was analyzed and inaccurate control of sample amount, position and temperature due to manual sample introduction [68]. Beyer et al. developed and evaluated an automated in-column pyrolysis-GC/MS system which they found to offer new opportunities for quantitation of polymers or other high molecular weight materials due to high reproducibility of peak areas [12]. The system included the option to work in normal injection mode and in pyrolysis mode simultaneously, thus facilitating the analysis of compounds such as additives in polymers, and the characterisation of the non-volatile fraction in a single run.

Considerations regarding the advantages and disadvantages of in-column pyrolysis have led to the recent development of a new system. Non-discriminating pyrolysis-GC, like in-column pyrolysis, is specifically designed to minimize the transfer losses of larger fragments from the pyrolysis unit to the GC column so that important structural information among other things can be obtained. Several designs have been developed and tested but the general configuration of a non-discriminating pyrolysis system is much like a normal Py-GC/MS in that the pyrolysis step is performed external to the GC and not in-line with the GC column in the GC oven (Fig. 4). Instead of a conventional pyrolyzer, pyrolysis occurs in an inert, Silcosteel capillary tube which is interfaced to the GC through a septumless injector in the GC injection port. The sample is secured inside the capillary tube using fused-silica wool plugs, the narrowness of the tube assuring that the temperature at the sample remains consistent with that at the heating element at all times. Pyrolysis of the sample is achieved using an electric current. The addition of a ceramic shield ensures the capillary pyrolysis temperature is not affected by external air currents. An inert gas supply to the capillary column during pyrolysis flushes the pyrolyzates out of the hot zone thus preventing secondary reactions and allowing for the recovery of higher molecular weight products through post-heating. A more detailed description of the instrumentation is available elsewhere [68]. The technique can be used for any type of material and despite its novelty, has already been used to study samples including synthetic and naturally occurring polymers [69]. In a study by Parsi et al., the performance of non-discriminating Py-GC/MS in the characterisation of natural organic matter (NOM) was assessed [70]. The results were compared to those also obtained using a filament and a Curie-point pyrolyzer. The study showed that the ambiguity caused by mass discrimination against larger fragments was dramatically reduced with non-discriminating Py-GC/MS compared to that of conventional pyrolysis approaches. Larger fragments such as traces of cholesterol in the pyrolysis of chitin were detected, which could not be observed with the commercial pyrolyzers. Furthermore, the macromolecular pyrolyzates showed a greater abundance in the pyrograms of various polyaromatic and long-chain aliphatic compounds obtained via non-discriminating Py-GC/MS. In another study, non-discriminating Py-GC/MS was used for the detection of ergosterol in various samples [70]. As the major sterol constituent in fungi, ergosterol is an essential chemical indicator of fungal contamination. Results showed that it was clearly detected in all of the samples and the authors reported that the benefits of non-discriminating pyrolysis including no sample preparation, small sample size and short analysis time, far outweighed those of other techniques. The profiling of fatty acids in bacterial biomasses using non-discriminating TMAH induced thermochemolysis Py-GC/MS has also been reported [71]. 
Journal of Chromatography A 1186 (2008) 51-66

On the whole, not only is the performance of the modified non-discriminating pyrolysis system much better than the original in-column pyrolysis system, it is also much easier to use. It offers great potential for the future analysis of high molecular weight pyrolyzates.

\section{Thermal degradation}

The kinetics of thermal degradation and structure determination of polymers and co-polymers has been covered in great detail in other reviews [2-3,72] and with little development in this area it is best to refer to those papers.

\subsection{Degradation properties}

Degradation results from free radical reactions initiated by bond breaking within the molecules; the bond that is more easily broken will be favoured. Thermal and environmental conditions, such as temperature and additional reactants, can affect both the extent and route of degradation of a polymeric material and the nature (physical and chemical) and quantity of molecular species generated by pyrolysis. Molecular degradation of a sample will occur as soon as the temperature is high enough to initiate bond breaking, but at this point will not necessarily yield much useful product [1]. With much higher temperatures, other bonds will break simultaneously, creating very small and non-specific free radicals. Generally, the higher the temperature, the smaller the radicals and molecules produced. The optimum pyrolysis temperature, which will be different for every polymer, is the point at which degradation produces a wide array of chemically useful products. Poly $\alpha$-methylstyrene for example yields $100 \%$ of monomer at $500^{\circ} \mathrm{C}, 88.5 \%$ at $800^{\circ} \mathrm{C}$ and only $37.7 \%$ at $1200^{\circ} \mathrm{C}$ [73]. These products, identified using GC/MS, can provide a fingerprint of the original polymer and copolymer composition and microstructure and help determine the degradation mechanisms.

The chemical composition of a polymer can also affect its degradation properties. Stauffer discussed how the substitution of a hydrogen atom with a $\mathrm{CH}_{3}$ group can alter the point at which the polymer chain breaks, affecting the degradation route and amount of product yielded [73].

Low level compounds added to a polymer, intended to alter its physical or chemical properties, are another factor which may influence its degradation properties and make the analysis of its products very challenging. Some additives can be thermally removed from the polymer before they degrade by heating the sample to a sub-pyrolysis temperature. In this instance the polymer undergoes degradation at a set pyrolysis temperature and the pyrogram should only contain peaks from the polymer itself. However, polymer additives present a problem in that they cannot be removed and must be pyrolysed along with the polymer matrix. The degradation behaviour of the original polymer and the additive will differ due to differences in their size, structure and composition therefore products generated from additives are often overshadowed by products generated from the polymer itself. More complex macromolecular additives produce even more degradation products upon pyrolysis, significantly changing the appearance of the pyrogram by reducing the size of other peaks. Recently, a multi-step approach has been used to thermally separate compound families at intervals during pyrolysis in order to simplify the pyrograms [74].

\subsection{Mechanisms}

Pyrolysis products reflect the molecular structure, free radical stability, substitution and internal rearrangements of the polymers constituting the sample material [1]. Thus, the degradation mechanisms undertaken are dependent upon the structure and bond dissociation energies of the 


\section{Journal of Chromatography A 1186 (2008) 51-66}

polymers. Consequently a polymer may take multiple degradation routes simultaneously. Identical molecules, heated to the same temperature will break apart and rearrange in the same characteristic way. The understanding of these mechanisms has led to improved interpretations of pyrograms. The three main mechanisms include random scission, side-group scission, and monomer reversion [73].

Random scission involves the random breaking of the polymer's C-C bonded backbone as all the bonds are of equal strength, resulting in the formation of products including, alkanes, alkenes and alkadienes of smaller sizes. Figure 5 shows the random scission of polyethylene. Upon pyrolysis the products formed can be seen clearly on a chromatogram as a familiar series of "triplet" peaks.

Side-group scission occurs when the side groups attached to the backbone are broken away resulting in the backbone becoming polyunsaturated. Its subsequent rearrangement produces aromatic compounds such as benzene, toluene, ethylbenzene, styrene and naphthalene as shown in Figure 6. Polymers including styrene, vinyl and some rubbers will undergo side-group scission.

During monomer reversion, the polymer simply unzips and reverts back to its original monomeric version otherwise referred to as depolymerisation. Usually only one predictable compound is produced. Polymers known to undergo this mechanism include polymethylmethacrylate (Fig. 7), polytetrafluoroethylene, poly $\alpha$-methylstyrene and polyoxymethylene.

Other mechanisms do exist but are not as common as those mentioned above; cross-linking and char formation is one of them. The occurrence of more cross-linking within the polymer molecules during pyrolysis ultimately strengthens the product, creating only a small number of volatiles. Typical polymers undergoing this route include polyacrylonitriles or phenolic resins. The thermal behaviour and degradation mechanisms, or rearrangements, in the pyrolysis of natural and synthetic polymeric materials, as well as other organic compounds, are continually being investigated.

It has been noted how, under various temperatures for the pyrolysis of polymers, traditional PyGC/MS is unable to distinguish the main degradation mechanism and evolved product distribution at specific temperature regions [75]. Whilst studying the pyrolysis of poly(aryl-ether-ether-ketone) and poly(arylene sulfone)s, Perng and co-workers overcame this issue by using stepwise pyrolysis-GC/MS. The method facilitated consecutive heating of the sample at fixed temperature intervals, thus achieving narrow temperature pyrolysis conditions and enabling the dominant pyrolysis mechanisms to be obtained [76,77]. A similar study of the thermal degradation mechanism of poly(ether imide) has also been reported [75]. The major mechanisms determined were two-stage pyrolysis, involving main-chain random scission and carbonization. Guo et al. identified the thermal degradation behaviour of a novel phosphorous-containing aromatic poly(ester amide) (ODOP-PEA) compound using Py-GC/MS [78]. Results suggested that bond cleavage of the pendant phosphorous groups occurred initially but maximum decomposition was attributed to the main chain scission at higher temperatures. High resolution Py-GC/MS was applied to analyse the degradation products of benzocyclobutene-terminated imide polymers, a kind of thermoset polymer [79]. Degradation mechanisms including, thermal cleavage, chain transfer, isomerization and cyclizations, were suggested and the relationship between polymer structure and pyrolyzates was discussed.

It is important to recognize that the dominant degradation mechanisms or pathways undertaken during pyrolysis of a sample might not necessarily be the same for each type of material. Most examples given above relate to the analysis of synthetic polymers however a significant number of samples analyzed by Py-GC are of natural origin. For example, Sun and co-workers used a microfurnace Py-GC/MS to analyse the thermal behaviour of vitamin $\mathrm{D}_{3}[80]$. The study was focussed on understanding what products were formed during the pyrolysis process in an attempt to identify the ingredient variation of the vitamin $\mathrm{D}_{3}$ that exists as crude and/or additive forms in foods under high temperatures. Furthermore, a number of studies on the analysis of natural organic matter using Py-GC methods have reported the formation of carbonaceous residue through charring as one of the major degradation processes [9]. 


\section{Journal of Chromatography A 1186 (2008) 51-66}

Pyrolysis-GC has also been used to study the influence of additives on the thermal degradation pathways of polymers. Ishikawa et al. studied the thermal degradation and flame retardancy of polycarbonate with the addition of a variety of different flame retardant chemicals using Py-GC/MS [81]. Different mechanisms were observed including hydrolysis, bond cleavage and cross-linking. Another study focused on the thermal degradation of a polycarbonate containing methylphenyl-silicone additive [82]. With the use of Py-GC/MS they deduced the addition of silicone could promote crosslinking and char formation as the mass loss rate of PC in the major degradation step was decreased. Bond scission was another proposed degradation route, thought to have produced the main volatile decomposition products of the PC-silicone blends. Bertini and Zuev investigated the influence of fullerene $\mathrm{C} 60$ additives on the thermal behaviour and degradation mechanism of fully aromatic regular polyesters using Py-GC/MS [83]. The presence of fullerene, being an efficient radical acceptor, was found to alter the decomposition from a radical pathway to a non-radical pathway. Jakab and Omastova studied the thermal decomposition of carbon black composites, used as a reinforcing agent and filler, with polyethylene (PE), polypropylene (PP) and polyisobutylene (PIB) [84]. Results of PyGC/MS experiments determined that the product distribution of polymers was dependent upon the level of volatility of the carbon black. The product distribution of both PE/carbon black composites and $\mathrm{PP} /$ carbon black composites indicated that carbon black participated in a hydrogenation process. Moreover, the formation of several other isomers during the degradation of PP composites also indicated that carbon black promoted other mechanisms including, chain scission and radical transfer reactions. Depolymerisation was observed in the decomposition of PIB composites in the presence of carbon black.

\section{Applications}

\subsection{Art materials}

The chemical, physical and structural characterization of materials such as glues, paints, pigments, binders and varnishes used to create artistic masterpieces, continues to provide art historians and conservators with precious information. This knowledge enables restoration and conservation work to be carried out properly without causing any damage to the original artifacts [85] and also helps to understand the techniques adopted by the artists. The organic materials used as binders in art media have received considerable attention. A review by Colombini and Modugno discusses the application of chromatographic techniques including Py-GC for the characterisation of proteinaceous binders such as animal skins or bones, egg and milk, or casein in artistic paintings [86]. Ling et al. attempted to characterize the natural binding media used in ancient Chinese artworks including non-proteinaceous materials such as Chinese lacquer, tung oil, deer glue, and peach gum using Py-GC/MS [87]. The kinds of natural resins used as the main ingredients in varnishes and binding media have also been assayed [88], including terpenoid resins [89,90] and triterpenic resins from the Burseraceae family [91]. Several studies have focused on the analysis of different artists' paints. Chiavari et al. analysed lipid materials used in paint layers using an in-situ pyrolysis and silylation method [92]. A paper by Bruck \& Willard discusses the process of deformulation of paints in order to obtain ingredient and compositional information [93], and a paper by Scalarone \& Chiantore reviews separation techniques for the analysis of acrylic emulsion paints [94]. Natural dyes used in works of art, namely madder, curcuma, saffron and indigo, have also been analysed by Py-GC/MS [95], and finally an interesting study by Bonaduce and Colombini used Py-GC/MS to characterize beeswax from a sculpture called "The Plague" (1691-1694) by Gaetano Zumbo [96]. 
Journal of Chromatography A 1186 (2008) 51-66

\subsection{Biological samples}

Much work continues to be done in an effort to identify and differentiate biological materials such as microorganisms. A flash Py-GC/MS method was reported for the rapid screening of bacterial species in order to detect the presence of bacteriohopanepolyols [97] and more recently, Py-GC/FID was employed for the quantitative pyrolysis of three different bacterial strains [32]. Goodacre et al. [98] detected a simple biomarker for the rapid detection of Bacillus spores using curie-point Py-GC/MS, whilst Schwarzinger [99] identified specific marker compounds characteristic of fungi type. The development of a miniaturized Py-GC system for the rapid detection and identification of bacteria and other pathogens has also been proposed [100]. Furthermore, the use of analytical pyrolysis in bioterrorism studies has been evaluated [101]. In an interesting application, Buckley et al. used PyGC/MS to analyse the complex organic balms on tissues and wrappings from pharaonic animal mummies in an effort to understand the mechanism of preservation in comparison to that observed with human mummies [102]. Other applications of Py-GC in biological studies include the compositional analysis of Copoly(DL-Lactic/Glycolic Acid) used in the medical and pharmaceutical fields when applied to devices for wound closure, orthopedics and controlled drug release [103], and structural investigations of neuromelanin from the human substantia nigra in the brain in an attempt to determine if neuromelanin is involved in cell death in Parkinson's disease [104,105].

\subsection{Environmental}

Applications of Py-GC in environmental science continue to grow, as the benefits of the analytical technique are still being discovered. This is demonstrated in a paper by White et al. which describes four recent applications of Py-GC/MS fingerprinting of environmental samples [106]. Several studies on the analyses of particulate organic matter (POM) suspended in water have been reported, such as a paper by Yildiz et al. who used Py-GC/MS to investigate suspended POM in open and coastal waters of the southern Black Sea and found evidence in the pyrograms of 23 marker compounds characteristic of chlorophylls, lipids, carbohydrates and proteins formed during pyrolysis [107]. Volkman and Tanoue have reviewed the chemical and biological research carried out on POM in oceans across the globe and in doing so have discussed Py-GC/MS as a new approach [108]. In addition to the characterisation of particulate organic matter, research has been done on the organic matter in marine sediments. Fabbri et al. compared pyrolytic and lipid markers in the Adriatic Sea using semi-quantitative Py-GC/MS and classical GC/MS [109]. Much work has also been published on the analysis of soil [110,111]. A recent review on soil health discusses the progress that has been made in the development of molecular and analytical methods, including Py-GC/MS, and the application of these techniques in determining soil health status [112]. In another application, a Py-GC/MS method for the analysis of the UV-Babsorbing compounds in small numbers of pollen, spores and other microscopic entities was developed in order to allow research toward the effect of increased UV-B radiation on plants [113].

\subsection{Food and agriculture}

Foodstuffs have been routinely analyzed by Py-GC for decades because of its ability to analyse complex molecules such as proteins, polysaccharides and lipids. Halket and Schulten studied several whole foodstuffs namely ground roast coffee, rosehip tea, wheatmeal biscuit, chocolate drink powder and milk chocolate, and were able to differentiate them all by examining the molecular weight distributions of released volatiles and pyrolysis products in their spectra [114]. The identification and quantification of soy protein in ground beef has also been reported [115]. Several papers have 
described rapid Py-GC/MS derivatization methods for profiling of fatty acids in vegetable oils and animal fats [116], including a study by Fabbri et al. who used dimethyl carbonate and titanium silicate as non-toxic derivatising agents to analyse soybean, coconut, linseed, walnut and olive oil [117].

Agricultural applications of analytical pyrolysis are mostly focused on soil chemistry, more specifically soil structure and soil organic matter (SOM) dynamics and composition. Nierop et al. investigated the differences in the chemical composition of SOM within one soil series from three differently managed fields in The Netherlands [118]. Results using a combination of Py-GC/MS and thermally assisted hydrolysis and methylation with TMAH determined that SOM composition is hardly affected by organic farming compared to conventional management i.e. high tillage intensity and intensive fertilization. Similarly, Marinari and co-workers used carbon fraction pools and pyrolytic indices as an indication of SOM quality under organic and conventional management in central Italy [119]. Furthermore, Rodriguez et al. evaluated chemical-structural properties of SOM under different agronomical practices of the Venezuelan central plains by measuring the relative abundance of volatile organic products produced by pyrolysis [120], and the chemical composition of organic matter in various fresh and composted wastes has been characterized by Dignac et al. [121]. A comparison between organic and mineral fertilization in the investigation of chemical and biochemical changes in SOM has also been reported, in which the detection of high levels of water soluble organic carbon and aliphatic pyrolytic products confirmed that mineral fertilization caused greater alteration of native SOM than the organic amendments [122].

\subsection{Geochemistry and fuel sources}

Investigations involving petrochemical related materials, of which there are several categories, are not a new phenomenon in Py-GC studies. The structural characterisation and differentiation of kerogens for example has received much attention in previous years but despite great progress, some knowledge of their chemical structure and the mechanism by which they form and change in time on Earth is still limited. González-Vila and co-workers analysed a set of kerogen concentrates using PyGC/MS both in the presence and absence of TMAH so as to study their structural characteristics [123]. Results indicated that considerable amounts of functionalized compounds are bound to the macromolecular structure via ester and ether linkages. Petsch et al. analysed the weathering profiles of organic carbon-rich black shales in order to determine the loss and degradation of organic matter during weathering and its role in the geochemical carbon cycle [124]. A model for kerogen weathering was suggested involving non-selective oxidation and hydration followed by cleavage/dissolution of oxidized kerogen fragments. The chemical structure, source(s), and formation pathway(s) of kerogenlike organic matter in sediments from the northwestern Black Sea has also been investigated [125], as well as the molecular structure of kerogens from source rocks of the Tarim Basin [126]. A review of pyrolysis techniques in the molecular characterisation of environmental kerogen and humic substances and their application to geochemistry has been published by Yamamoto et al. [127].

Another area of geochemical research which has been greatly explored includes the compositional analysis of coal materials. The release behaviour of hydrocarbon components of pulverized coal has been investigated using Py-GC [128], as have the pyrolyzates of raw vitrinites and their residues from selected coal samples following a novel binary solvent extraction procedure [129]. The co-pyrolysis of coal and petroleum residues has been studied by Suelves et al. in an attempt to examine the synergetic effects on the yield of the main petrochemical pyrolysis products [130], and the structural characterisation of oil and coal tars using pyrolysis techniques have also been reported [131,132]. Other studies include the analysis of byproducts resulting from the combustion of coal, such as flyash [133]. 
Journal of Chromatography A 1186 (2008) 51-66

Additional research using Py-GC includes the study of both volatile and involatile organic compounds in extraterrestrial environments during planetary missions [134], and the examination of cuticles from fossil arthropods [135].

\subsection{Synthetic polymers}

Py-GC has developed considerably to become a routine tool for the identification and differentiation of synthetic polymers as well as the quantitative determination of monomers in copolymers. A great deal of research is now focused on the detection of low level chemical compounds in the polymers. There are many publications on this application of Py-GC however here only a brief overview is presented. Many examples have already been provided throughout the scope of this review, but the most frequently analysed synthetic products include plastics, rubbers, coatings and composites. The developments in analytical techniques for the analysis of polyolefins with respect to molar mass and chemical composition distribution have been addressed by Pasch [136]. A very recent study on the composition and microstructure of ethylene and propylene copolymers using Py-GC found it to be a very reliable and reproducible method [137]. Future developments regarding the technique were suggested, including the development of a novel pyrolysis and two-dimensional GC system (Py-GC $\times$ GC) which would further improve accuracy by facilitating enhanced separation of pyrolyzates and thus greatly reducing detection interferences. Wampler et al. have demonstrated a Py-GC/MS method from which monomer ratios in random and block copolymers of polyolefins, especially polyethylene and polypropylene can be obtained [138], and Evans et al. report an approach for the structural analysis of polyester thermosets [139]. The chemical composition of multicomponent acrylic resins, including ethyl acrylate-butyl methacrylate copolymers and ethyl acrylate-styrene-ethyl methacrylate terpolymers has been assayed [140], as well as the quantitative determination of poly(ethylacrylatemethylmethacrylate) layers on drug granules for pharmaceutical use [141]. The compositional and microstructural determination of water-based synthetic polymers in a latex system using a pre-pyrolysis derivatization step has also been described [142]. Furthermore, Learner analyzed the synthetic polymers used in the formulation of paints such as alkyd, polyvinyl acetate and nitrocellulose [143], and many authors have studied the pyrolysis patterns of rubbers using Py-GC [144], including Choi who assayed styrene-butadiene rubbers with differing microstructures [145].

\subsubsection{Detection of additives and contaminants}

Compounds added to polymeric materials in order to alter their physical or chemical properties in some way consist of fillers, pigments, antioxidants, stabilizers, flame retardants, plasticisers, lubricants, preservatives and other modifiers [74]. The effect additives have on the thermal degradation properties of a polymer has already been addressed. The determination of low level polymer additives in complex pyrograms is a subject briefly discussed by Wang in his earlier review on Py-GC [2], and despite several studies published since then, analytical development in this area has been slow. The key to the successful analysis of additives is to understand the properties they possess and to have knowledge of the polymers and their applications. Volatile and semi-volatile additives can usually be extracted from the matrix and analysed independently using GC methods. A fast Py-GC method has been described for the qualitative identification of plastic additives from samples of recycled and pure acrylonitrilebutadiene-styrene (ABS) originating from electronic waste [146]. The method combines the advantages of thermal desorption and flash pyrolysis by using a novel double-shot pyrolyzer; the low molecular weight additives are desorbed before the polymer chain undergoes decomposition. 
Journal of Chromatography A 1186 (2008) 51-66

More complex additives however cannot be extracted, and so pyrolysis of both the additive and the polymer must occur simultaneously. Identification of the pure additive is dependent upon careful interpretation of the intricate array of peaks present on the pyrogram and making distinctions between peaks which are chemically or chromatographically different. Recent investigations have found the selective ion monitoring mode of MS detectors to be the most informative approach in this case as it immediately simplifies the identification process [74]. Wang has published a series of papers analyzing several types of polymer additives, namely plasticizers, flame retardants, lubricants and antioxidants, in order to demonstrate the utility of Py-GC as a good tool for the characterisation of such polymeric systems [147-150]. The advantages of using Py-GC in each case have been discussed. Yang et al. investigated the effects of different inorganic fillers on the natural photo-oxidation degradation of high-density polyethylene (HDPE) using Py-GC/MS [151]. Results showed that whilst some fillers, e.g. $\mathrm{CaCo}_{3}$ and wollastonite, stabilized HDPE a little, other inorganic fillers including kaolin, diatomite and mica, accelerated the degradation. In an interesting application Py-GC was used to analyse the ABS plastic material used to make faulty Takata press release buttons in automobile seat belts, to determine if a UV stabilizer had been added [152]. A UV stabilizer was detected and validated using mass spectrometry.

Additives are also incorporated into natural polymers for the same reasons as they are added to synthetic polymers and they can be detected using the same methods. Techniques for applying internal standards for the quantification of typical chemical paper additives using Py-GC with mass selective detection have been suggested and demonstrated by Odermatt et al [153]. Zhu and co-workers studied the pyrolysis products of cotton and flame retardant cotton fabrics in an attempt to understand their thermal degradation mechanisms and thus the fire-resisting functions of the materials [154].

\subsection{Forensic}

Pyrolysis-GC is a well established technique in forensic analysis often used by forensic chemists to analyse a vast array of polymeric materials. The literature available is therefore extensive and it includes many different applications. Certainly one of the most investigated areas is document analysis, including the classification and differentiation of photocopy toners and the analysis of inks. Studies on the examination of machine copier toners using Py-GC date back to the 1980's. Zimmerman et al. analysed thirty-five different photocopy toners and respective machine copied documents in an attempt to establish a library of spectra from which an unknown toner extracted from a questioned document may be matched [155]. Levy and Wampler used Py-GC/MS to analyze a variety of photocopies produced by different manufacturers of copying instruments and found specific chemical differences in the toner materials used in each make of copier [156]. Similarly, Munson separated photocopy toner material from photocopies from 62 different machines into 18 classes depending on the presence or absence of peaks in the pyrograms [157] and Chang et al. described a PyGC/FID method for the differentiation of photocopier toners using a Curie-point pyrolyzer and a computer-assisted library search method [158]. A less damaging technique for the identification of black toner material using Py-GC with mass selective detection has also been reported involving the heat transfer of the toner from the paper to a medium [159]. More recent work includes the forensic discrimination of photocopy and printer toners using multivariate statistics [160], and a study of solvents in inkjet printings which found varying proportions of different solvents in different inks [161]. A review on chromatographic and electrophoretic applications in ink analysis and the components of different types of inks has been published [162].

Besides photocopy toners and ink, the forensic analysis of packaging tapes and the adhesives is another area in which literature is readily available. The identification of trace amounts of synthetic adhesives has been achieved by $\mathrm{Li}$ et al. who incorporated simultaneous methylation in order to 


\section{Journal of Chromatography A 1186 (2008) 51-66}

measure the polar compounds [163]. Sakayanagi et al. used Py-GC/MS to identify 20 different products of colourless, transparent, pressure-sensitive adhesive polypropylene tapes, the results of which proved it to be such an effective method that it was applied to the analysis of a real forensic sample [164]. Furthermore, the deteriorated rubber-based pressure sensitive adhesives of three packaging tapes were analysed by Kumooka who determined that tackifiers including Coumarone resins, aromatic petroleum resins and $\beta$-pinene resins have higher resistance to oxidation than natural rubbers and aliphatic petroleum resins, and can still be identified by Py-GC/MS even after the deterioration [165]. A multi-step analysis of packaging tape has also been reported by using a Pyroprobe 5150 model which can be programmed to take the same sample material to a variety of temperatures automatically [166].

Py-GC has long been recognized as a standard method for the forensic analysis of other materials as well. Several papers have described methods for the identification and differentiation of automotive paint samples [167,168], and for the analysis of fibers [169]. Drugs and their metabolites have also been investigated, including a study by Takayasu and Ohshima who devised a Py-GC/MS method for the rapid analysis of methamphetamine and its analogs [170]. Another study proposed a protocol for the forensic detection and analysis of condom and personal lubricants in sexual assault cases $[171,172]$. Further applications of Py-GC in the field of forensic medicine and toxicology include the postmortem alcohol analysis of the synovial fluid and its availability as a biological specimen for the prediction of blood alcohol concentration and urine alcohol concentration in medico-legal cases [173], and the rapid analysis of pesticide components in blood and urine [174].

\section{Miscellaneous}

Future developments regarding Py-GC as a technique have been suggested. In their work on the composition and microstructure of synthetic copolymers, Wang et al. discussed the development of a novel pyrolysis and comprehensive two-dimensional GC system $(\mathrm{GC} \times \mathrm{GC})$ designed to further improve the accuracy achieved using conventional GC methods by facilitating enhanced separation of pyrolyzates [137]. Based on orthogonal separation principles, comprehensive $\mathrm{GC} \times \mathrm{GC}$ relies on a configuration comprising of two columns displaying different separation characteristics. The entire sample is first separated on a normal-bore capillary column under programmed temperature conditions. The effluent is then modulated and each subsequent small portion of eluate is refocused and re-injected onto the second column for further separation. As a result, the resolving power of the chromatograph is increased by over a factor of ten and the probability of coeluting compounds or detection interferences is greatly reduced. Comprehensive GC $\times$ GC not only simplifies sample preparation procedures but also provides higher sensitivity making it extremely well suited for the analysis of complex pyrolyzates. The advantages of this system have been demonstrated in a study by Parsi et al. who used non-discriminating pyrolysis combined with conventional GC/MS and comprehensive $\mathrm{GC} \times \mathrm{GC} / \mathrm{TOF}-$ MS to analyse the organic fraction of airborne particulate matter (PM) [69]. Whilst results obtained using conventional GC/MS provided insufficient chromatographic resolution to enable identification of PM volatiles and semi-volatiles due to many coelutions, those obtained using comprehensive GC $\times$ GC/TOF-MS showed a dramatic improvement in analyte separation and thus identification.

Other instrumental techniques involving pyrolysis without the GC separation step also exist but are beyond the scope of this review. Both direct pyrolysis mass spectrometry (DPMS) and direct pyrolysis fourier transform infrared spectrometry (DP/FTIR) involve the direct interfacing of the pyrolysis device to the detector. In both cases, the technique has been used in polymer analysis as a quick way of identifying primary degradation products which avoid secondary pyrolysis reactions, with minimal sample preparation. With DPMS, pyrolysis occurs under high vacuum and the readily volatilised pyrolyzates are immediately ionised and detected, preventing further thermal degradation. This 
Journal of Chromatography A 1186 (2008) 51-66

technique has been used in a number of studies in order to obtain characteristic information much faster and to study the primary degradation pathways of polymers [175-181]. With DP/FTIR, the pyrolysis instrument (usually a platinum coil Pyroprobe) is designed to fit into the sample compartment of a standard FTIR detector with the use of a specially designed interface. The filament of the Pyroprobe is placed directly in the light path so that upon pyrolysis, the volatile pyrolyzates diffuse immediately into the beam where they are detected. Rapid analysis in the beam eliminates any chance of condensation. DP/FTIR is therefore a fast and easy method of obtaining a wide range of information on polymeric materials. Several studies have demonstrated its potential [182-184].

\section{Conclusion}

Py-GC has evolved to become a routine analytical tool for the characterisation and differentiation of polymers, both natural and synthetic. Since 1999, several types of thermal analysis equipment have been developed to improve the analytical scope of Py-GC. Besides conventional pyrolyzers, the introduction of laser pyrolysis has become a new phenomenon for Py-GC. Laser energy used as a fragmentation source has facilitated controlled pyrolysis of specific regions on a sample, providing useful data on the molecular compositional units of macromolecules in situ. The very recent development of a non-discriminating Py-GC system has been designed to overcome the problems associated with traditional pyrolyzers relating to sample losses and discrimination of high-molecular weight compounds. Having already been used in a range of applications it offers great potential for the future analysis of macromolecular structures. Furthermore, the development of a novel double-shot pyrolyzer incorporating both thermal desorption and flash pyrolysis, has become a useful instrument for the fast identification of low molecular weight polymer additives. Future developments in Py-GC technology have also been suggested, which include the use of comprehensive GC $\times$ GC for the enhanced separation and detection of pyrolyzates.

\section{Acknowledgments}

The authors want to thank those who granted permission for the inclusion of the figures shown in this review.

\section{References}

[1] T.P. Wampler, J. Chromatogr. A 842 (1999) 207.

[2] F.C.-Y. Wang, J. Chromatogr. A 843 (1999) 413.

[3] S.C. Moldoveanu, J. Microcol. Sep. 13 (2001) 102.

[4] R.D. Blackledge, Forensic Sci. Rev. 4 (1992) 1.

[5] S. Tsuge, H. Ohtani, C Watanabe, Y. Kawahara, Am. Lab. 35 (2003) 32.

[6] H. Schmidt, F.K. Tadjimukhamedov, K.M. Douglas, S. Prasad, G.B. Smith, G.A. Eiceman, J. Anal. Appl. Pyrol. 76 (2006) 161.

[7] F.W. Fifield, D. Kealey, Principles and Practice of Analytical Chemistry, Blackwell, Oxford, UK, 5th ed., 2000, p. 499.

[8] S. Tsuge, H. Ohtani, C Watanabe, Am. Lab. 35 (2003) 16.

[9] Z. Parsi, N. Hartog, T. Górecki, J. Poerschmann, J. Anal. Appl. Pyrol. 79 (1-2 SPEC. ISS.) (2007) 9.

[10] S. Buco, M. Moragues, P. Doumenq, A. Noor, G. Mille, J. Chromatogr. A 1026 (2004) 223.

[11] N.K. Meruva, L.A. Metz, S.R. Goode, S.L. Morgan, J. Anal. Appl. Pyrol. 71 (2004) 313.

[12] D. Beyer, P. Eckerle, H. Cortes, W. Engewald, K. Dettmer, Chromatographia 62 (2005) 417. 
Journal of Chromatography A 1186 (2008) 51-66

[13] E. Jamin, S. Chevolleau, C. Touzet, J. Tulliez, L. Debrauwer, Anal. Bioanal. Chem. 387 (2007) 2931.

[14] J.G. Wilkes, L.G. Rushing, J-F. Gagnon, S.A. McCarthy, F. Rafii, A.A. Khan, C.A. Kaysner, T.M. Heinze, J.B. Sutherland, Anton van Leeuw. Int J.G. 88 (2005) 151.

[15] J.G. Wilkes, L. Rushing, R. Nayak, D.A. Buzatu, J.B. Sutherland, J. Microbiol. Methods 61 (2005) 321.

[16] P.M. Peacock, C.N. McEwen, Anal. Chem. 78 (2006) 3957.

[17] A.L. Sessions, J. Sep. Sci. 29 (2006) 1946.

[18] R. Pel, V. Floris, H.J. Gons, H.L. Hoogveld, J. Phycol. 40 (2004) 857.

[19] R. Pel, V. Floris, H. Hoogveld, Freshwater Biol. 49 (2004) 546.

[20] M.A. Sephton, I. Gilmour, Planet.Space Sci. 49 (2001) 465.

[21] G. Gleixner, R. Bol, J. Balesdent, Rapid Commun. Mass Spectrom. 13 (1999) 1278.

[22] S. Prasad, H. Schmidt, P. Lampen, M. Wang, R. Güth, J.V. Rao, G.B. Smith, G.A. Eiceman, Analyst 131 (2006) 1216.

[23] A.P. Snyder, A. Tripathi, W.M. Maswadeh, J. Ho, M. Spence, Field Anal. Chem. Tech. 5 (2001) 190.

[24] J. Yinon, Trends Anal. Chem. 21 (2002) 259.

[25] R.P. Erickson, A. Tripathi, W.M. Maswadeh, A.P. Snyder, P.A. Smith, Anal. Chim. Acta 556 (2006) 455.

[26] S. Park, T. Yoon, Desalination 208 (2007) 181.

[27] J. Odermatt, D. Meier, K. Leicht, R. Meyer, T. Runge, J. Anal. Appl. Pyrol. 68-69 (2003) 269.

[28] U. Räisänen, I. Pitkänen, H. Halttunen, M. Hurtta, J. Therm. Anal.Calorim. 72 (2003) 481.

[29] J. Suuronen, I. Pitkänen, H. Halttunen, R. Moilanen, J. Therm. Anal.Calorim. 69 (2002) 359.

[30] M. Ristolainen, R. Alén, J. Toivanen, J. Anal. Appl. Pyrol. 52 (1999) 225.

[31] A.V. Marques, H. Pereira, J. Rodrigues, D. Meier, O. Faix, J. Anal. Appl. Pyrol. 77 (2006) 169.

[32] H. Schmidt, F.K. Tadjimukhamedov, K.M. Douglas, S. Prasad, G.B. Smith, G.A. Eiceman, J. Anal. Appl. Pyrol. 76 (2006) 161.

[33] J. Odermatt, R. Meyer, D. Meier, R. Ettl, J. Pulp Pap. Sci. 29 (2003) 1.

[34] M. Mähnen, J. Astola, J. Poutanen, R. Alén, E. Pääkkönen, J. Inj. Molding Tech. 4 (2000) 84.

[35] B.L. Li, J.K. Ding, F.N. Yan, C.C. Fan, Se Pu (Chin. J. Chromatogr.) / Zhongguo Hua Xue Hui 18 (2000) 364.

[36] N. Tzamtzis, A. Pappa, A. Mourikis, Polym. Degrad. Stab. 66 (1999) 55.

[37] E. Jarde, F. Vilmin, L. Mansuy, P. Faure, J. Anal. Appl. Pyrol. 71 (2004) 553.

[38] A.B. Ross, S. Junyapoon, K.D. Bartle, J.M. Jones, A. Williams, J. Anal. Appl. Pyrol. 58-59 (2001) 371.

[39] F.C-Y. Wang, Anal. Chem. 71 (1999) 2037.

[40] C. Flodin, M. Ekelund, H. Borén, A. Grimvall, Chemosphere 34 (1997) 2319.

[41] V.A. Yaylayan, L. Haffenden, F.L. Chu, A. Wnorowski, Ann. N.Y. Acad. Sci. 1043 (2005) 41.

[42] L.J.W. Heffenden, V.A. Yaylayan, J. Agric. Food Chem. 53 (2005) 9742.

[43] L. Osete-Cortina, M.T. Doménech-Carbó, J. Chromatogr. A 1065 (2005) 265.

[44] L. Osete-Cortina, M.T. Doménech-Carbó, J. Chromatogr. A 1127 (2006) 228.

[45] A. Asperger, W. Engewald, G. Fabian, J. Anal. Appl. Pyrol. 52 (1999) 51.

[46] A. Asperger, W. Engewald, G. Fabian, J. Anal. Appl. Pyrol. 61 (2001) 91.

[47] I. Tanczos, G. Pokol, J. Borsa, T. Tóth, H. Schmidt, J. Anal. Appl. Pyrol. 68-69 (2003) 173.

[48] K. Ikeya, Y. Ishida, H. Ohtani, A. Watanabe, J. Anal. Appl. Pyrol. 75 (2006) 174.

[49] J.M. Challinor, J. Anal. Appl. Pyrol. 61 (2001) 3.

[50] J.M. Halket, V.G. Zaikin, Eur. J. Mass Spectrom. 12 (2006) 1.

[51] P.F. Greenwood, S.C. George, M.A. Wilson, K.J. Hall, J. Anal. Appl. Pyrol. 38 (1996) 101. 
Journal of Chromatography A 1186 (2008) 51-66

[52] L.A. Metz, N.K. Meruva, S.L. Morgan, S.R. Goode, J Anal. Appl. Pyrol. 71 (2004) 327.

[53] P.F. Greenwood, S.C. George, K. Hall, Org. Geochem. 29 (1998) 1075.

[54] P.F. Greenwood, E. Zhang, F.J. Vastola, P.G. Hatcher, Anal. Chem. 65 (1993) 1937.

[55] M.S. Thomsen, H. Egsgaard, J Anal. Appl. Pyrol. 34 (1995) 243.

[56] Y. Choi, H. Lee, S.T. Foutain, D.M. Lubman, J. Am. Soc. Mass Spectrom. 5 (1994) 106.

[57] W.T. Ristau, N.E. Vanderborgh, Anal. Chem. 44 (1972) 359.

[58] D.L. Fanter, R.L. Levy, C.J. Wolf, Anal. Chem. 44 (1972) 43.

[59] N.E. Vanderborgh, W.T. Ristau, J. Chromatogr. Sci. 11 (1973) 535.

[60] S. Armitage, S. Saywell, C. Roux, C. Lennard, P. Greenwood, J. Forensic Sci. 46 (2001) 1043.

[61] S.A. Stout, R. Lin, Org. Geochem. 18 (1992) 229.

[62] S.A. Stout, Int. J. Coal Geol., 24 (1993) 309.

[63] P.F. Greenwood, J.D.H. van Heemst, E.A. Guthrie, P.G. Hatcher, J. Anal. Appl. Pyrol. 62 (2002) 365.

[64] S.A. Stout, K. Hall, J. Anal. Appl. Pyrol. 21 (1991) 195.

[65] J.M. Challinor, J. Anal. Appl. Pyrol. 25 (1993) 349.

[66] A. Asperger, W. Engewald, G. Fabian, J. Anal. Appl. Pyrol. 50 (1999) 103.

[67] F-J. Göbbels, W. Püttmann, Water Res. 31 (1997) 1609.

[68] Z. Parsi, T. Górecki, J. Poerschmann, J. Anal. Appl. Pyrol. 74 (2005) 11.

[69] Z. Parsi, T. Górecki, J. Poerschmann, LC-GC Eur. 18 (2005) 582.

[70] Z. Parsi, T. Górecki, J Chromatogr. A 1130 (2006) 145.

[71] J. Poerschmann, Z. Parsi, T. Górecki, J. Augustin, J. Chromatogr. A 1071 (2005) 99.

[72] F.C-Y Wang, J. Anal. Appl. Pyrol. 71 (2004) 83.

[73] E. Stauffer, Sci. Justice 43 (2003) 29.

[74] K.D. Jansson, C.P. Zawodny, T.P. Wampler, J. Anal. Appl. Pyrol. 79 (2007) 353.

[75] L.H. Perng, J. Appl. Polym. Sci. 79 (2001) 1151.

[76] C.J. Tsai, L.H. Perng, Y.C. Ling, Rapid Comm. Mass Sp. 11 (1997) 1987.

[77] L.H. Perng, J. Polym. Sci. Part A: Polym. Chem 38 (2000) 583.

[78] W. Guo, W-T. Leu, S-H. Hsiao, G-S. Liou, Polym. Degrad. Stab. 91 (2006) 21.

[79] Y. Zhang, X. Shen, F. Huang, Thermochim. Acta 430 (2005) 15.

[80] Y. Sun, B. Liu, G. Wang, R. Zhang, B. Xie, Ann. Chim-Rome 95 (2005) 559.

[81] T. Ishikawa, I. Maki, T. Koshizuka, K. Takeda, J. Soc. Mat. Sci., Japan 53 (2004) 1301.

[82] W. Zhou, H. Yang, J. Zhou, J. Anal. Appl. Pyrol. 78 (2007) 413.

[83] F. Bertini, V.V. Zuev, Polym. Degrad. Stab. 91 (2006) 3214.

[84] E. Jakab, M. Omastová, J. Anal. Appl. Pyrol. 74 (2005) 204.

[85] L. Osete-Cortina, M.T. Doménech-Carbó, J. Anal. Appl. Pyrol. 76 (2006) 144.

[86] M.P. Colombini, F. Modugno, J. Sep. Sci. 27 (2004) 147.

[87] H. Ling, N. Maiqian, G. Chiavari, R. Mazzeo, Microchem. J. 85 (2007) 347.

[88] S. Prati, S. Smith, G. Chiavari, Chromatographia 59 (2004) 227.

[89] M.T. Doménech-Carbó, L. Osete-Cortina, J. De La Cruz Canizares, F. Bolívar-Galiano, J.

Romero-Noguera, M.A. Fernández-Vivas, I. Martín-Sánchez, Anal.Bioanal.Chem. 385 (2006) 1265.

[90] M.T. Doménech-Carbó, S. Kuckova, J. De La Cruz Canizares, L. Osete-Cortina, J. Chromatogr. A 1121 (2006) 248.

[91] J. De la Cruz-Canizares, M-T. Doménech-Carbó, J-V. Gimeno-Adelantado, R. Mateo-Castro, F. Bosch-Reig, J. Chromatogr. A 1093 (2005) 177.

[92] G. Chiavari, D. Fabbri, S. Prati, Chromatographia 53 (2001) 311.

[93] M.L. Bruck, G.F. Willard, Met. Finish. 104 (2006) 23.

[94] D. Scalarone, O. Chiantore, J. Sep. Sci. 27 (2004) 263.

[95] M.J. Casas-Catalán, M.T. Doménech-Carbó, Anal. Bioanal. Chem. 382 (2005) 259. 
Journal of Chromatography A 1186 (2008) 51-66

[96] I. Bonaduce, M.P. Colombini, J. Chromatogr. A 1028 (2004) 297.

[97] M.A. Sugden, H.M. Talbot, P. Farrimond, Org. Geochem. 36 (2005) 975.

[98] R. Goodacre, B. Shann, R.J. Gilbert, É.M. Timmins, A.C. McGovern, B.K. Alsberg, D.B. Kell, N.A. Logan, Anal. Chem. 72 (2000) 119.

[99] C. Schwarzinger, J. Anal. Appl. Pyrol. 74 (2005) 26.

[100] C. Mowry, C. Morgan, Q. Baca, R. Manginell, R. Kottenstette, P. Lewis, G. Frye-Mason, Proceedings of SPIE - Int. Soc. Opt. Eng. 4575 (2001) 83.

[101] R. Łakomy, Prz. Epidemiol. 55 (2001) 197.

[102] S.A. Buckley, K.A. Clark, R.P. Evershed, Nature 431 (2004) 294.

[103] K. Urakami, A. Higashi, K. Umemoto, M. Godo, C. Watanabe, K. Hashimoto, Chem. Pharm. Bull. 49 (2001) 203.

[104] A. Dzierzega-Lecznar, S. Kurkiewicz, K. Stepien, E. Chodurek, T. Wilczok, T. Arzberger, P. Riederer, M. Gerlach, J. Am. Soc. Mass Spectrom. 15 (2004) 920.

[105] A. Dzierzega-Lecznar, S. Kurkiewicz, K. Stepien, E. Chodurek, P. Riederer, M. Gerlach, J. Neural Transm. 113 (2006) 729.

[106] D.M. White, D.S. Garland, L. Beyer, K. Yoshikawa, J. Anal. Appl. Pyrol. 71 (2004) 107.

[107] Y.Çoban-Yildiz, G. Chiavari, D. Fabbri, A.F. Gaines, G. Galletti, S. Tuğrul, Marine Chem. 69 (2000) 55.

[108] J.K. Volkman, E. Tanoue, J. Oceanog. 58 (2002) 265.

[109] D. Fabbri, F. Sangiorgi, I. Vassura, Anal. Chim. Acta 530 (2005) 253.

[110] C.J. Evans, R.P. Evershed, H.I.J. Black, P. Ineson, Anal. Chem. 75 (2003) 6056.

[111] N. Poirier, S.P. Sohi, J.L. Gaunt, N. Mahieu, E.W. Randall, D.S. Powlson, R.P. Evershed, Org. Geochem. 36 (2005) 1174.

[112] M.E. Arias, J.A. González-Pérez, F.J. González-Vila, A.S. Ball, Int. Microbiol. 8 (2005) 13.

[113] P. Blokker, D. Yeloff, P.Boelen, R.A. Broekman, J. Rozema, Anal. Chem. 77 (2005) 6026.

[114] J.M. Halket, H.R. Schulten, Z. Lebensm. Unters. Forsch 186 (1988) 201.

[115] S.K. Raghavan, C.T. Ho, H. Daun, J. Chromatogr. 351 (1986) 195.

[116] J.M. Challinor, J. Anal. Appl. Pyrol. 37 (1996) 185.

[117] D. Fabbri, V. Baravelli, G. Chiavari, S. Prati, J. Chromatogr. A 1100 (2005) 218.

[118] K.G.J. Nierop, M.M. Pulleman, J.C.Y. Marinissen, Soil Biol. Biochem. 33 (2001) 755.

[119] S. Marinari, K. Liburdi, G. Masciandaro, B. Ceccanti, S. Grego, Soil Till. Res. 92 (2007) 10.

[120] B. Rodriguez, M. España, E. Cabrera De Bisbal, Interciencia 29 (2004) 461.

[121] M-F. Dignac, S. Houot, C. Francou, S. Derenne, Org. Geochem. 36 (2005) 1054.

[122] S. Marinari, G. Masciandaro, B. Ceccanti, S. Grego, Bioresource Technol. 98 (2007) 2495.

[123] F.J. González-Vila, A. Amblés, J.C. del Río, L. Grasset, J. Anal. Appl. Pyrol. 58-59 (2001) 315.

[124] S.T. Petsch, R.A. Berner, T.I. Eglinton, Org. Geochem. 31 (2000) 475.

[125] A. Garcette-Lepecq, S. Derenne, C. Largeau, I. Bouloubassi, A. Saliot, Org. Geochem. 31 (2000) 1663.

[126] W. Jia, P. Peng, Sci. China Ser. D 48 (2005) 313.

[127] S. Yamamoto, H. Yoshioka, R. Ishiwatari, Bunseki Kagaku 56 (2007) 71.

[128] J. Jin, Z. Zhang, J. Zhang, Huagong Xuebao/J. Chem. Ind. Eng. 58 (2007) 217.

[129] D. Liu, P. Peng, Chinese Sci. Bull.51 (2006) 2103.

[130] I. Suelves, R. Moliner, M.J. Lazaro, J. Anal. Appl. Pyrol. 55 (2000) 29.

[131] M-J. Lazaro, R. Moliner, I. Suelves, A.A. Herod, R. Kandiyoti, Fuel 80 (2001) 179.

[132] C.A. Islas, I. Suelves, J.F. Carter, W. Li, T.J. Morgan, A.A. Herod, R. Kandiyoti, Rapid Commun. Mass Spectrom. 16 (2002) 774.

[133] Eight Step Analysis of Flyash, CDSolutions, Oxford, PA, 2007.

[134] F. Raulin, R. Sternberg, D. Coscia, C. Vidal-Madjar, M-C. Millot, B. Sébille, G. Israel, Adv. Space Res. 23 (1999) 361. 
Journal of Chromatography A 1186 (2008) 51-66

[135] N.S. Gupta, R. Michels, D.E.G. Briggs, R.P. Evershed, R.D. Pancost, Proc. R. Soc. B 273 (2006) 2777.

[136] H. Pasch, Macromol. Symp. 165 (2001) 91.

[137] F.C-Y. Wang, D.J. Lohse, B.R. Chapman, B.A. Harrington, J. Chromatogr. A 1138 (2007) 225.

[138] T. Wampler, C. Zawodny, L. Mancini, J. Wampler, J. Anal. Appl. Pyrol. 68-69 (2003) 25.

[139] S.J. Evans, P.J. Haines, G.A. Skinner, J. Anal. Appl. Pyrol. 55 (2000) 13.

[140] S. Mao, H. Ohtani, S. Tsuge, J. Anal. Appl. Pyrol. 33 (1995) 181.

[141] A. Asperger, W. Engewald, T. Wagner, J. Anal. Appl. Pyrol. 49 (1999) 155.

[142] F.C-Y. Wang, Anal. Chem. 71 (1999) 4776.

[143] T. Learner, Stud. Conserv. 46 (2001) 225.

[144] Pyrolysis of Rubber with Antioxidant 6-PPD, CDSolutions, Oxford, PA, 2007.

[145] S-S. Choi, J. Anal. Appl. Pyrol. 62 (2002) 319.

[146] M. Herrera, G. Matuschek, A. Kettrup, J. Anal. Appl. Pyrol. 70 (2003) 35.

[147] F.C-Y. Wang, J. Chromatogr. A 883 (2000) 199.

[148] F.C-Y. Wang, J. Chromatogr. A 886 (2000) 225.

[149] F.C-Y. Wang, W.C. Buzanowski, J. Chromatogr. A 891 (2000) 313.

[150] F.C-Y. Wang, J. Chromatogr. A 891 (2000) 325.

[151] R. Yang, J. Yu, Y. Liu, K. Wang, Polym. Degrad. Stab. 88 (2005) 333.

[152] R.F. Dunn, R.H. McSwain, T. Mills, B. Malone, Eng. Fail. Anal. 12 (2005) 81.

[153] J. Odermatt, D. Meier, K. Leicht, R. Meyer, T. Runge, J. Anal. Appl. Pyrol. 68-69 (2003) 269.

[154] P. Zhu, S. Sui, B. Wang, K. Sun, G. Sun, J. Anal. Appl. Pyrol. 71 (2004) 645.

[155] J. Zimmerman, D. Mooney, M.J. Kimmett, J. Forensic Sci. 31 (1986) 489.

[156] E.J. Levy, T.P. Wampler, J. Forensic Sci. 31 (1986) 258.

[157] T.O. Munson, J. Forensic Sci. 34 (1989) 352.

[158] W-T. Chang, C-W. Huang, Y-S. Giang, J. Forensic Sci. 38 (1993) 843.

[159] J.A. De Koeijer, J.J.M. De Moel, Z Zagadnien Nauk Sadowych 46 (2001) 413.

[160] W.J. Egan, R.C. Galipo, B.K. Kochanowski, S.L. Morgan, E.G. Bartick, M.L. Miller, D.C. Ward, R.F. Mothershead II, Anal. Bioanal. Chem. 376 (2003) 1286.

[161] F. Partouche, B. Espanet, C. Villena, C. Murie, International Conference on Digital Printing Technologies (2005) 216.

[162] J.A. Zlotnick, F.P. Smith, J. Chromatogr. B 733 (1999) 265.

[163] B.L. Li, J.K. Ding, F.N. Yan, C.C. Fan, Se Pu (Chin. J. Chromatogr.) / Zhongguo Hua Xue Hui 18 (2000) 364.

[164] M. Sakayanagi, Y. Konda, K. Watanabe, Y. Harigaya, J. Forensic Sci. 48 (2003) 68.

[165] Y. Kumooka, Forensic Sci. Int. 163 (2006) 132.

[166] Multi-Step Analysis of Packaging Tape, CDSolutions, Oxford, PA, 2007.

[167] B.K. Kochanowski, S.L. Morgan, J. Chromatogr. Sci. 38 (2000) 100.

[168] T.P. Wampler, LC-GC N. Am. 23 (2005) 79.

[169] V. Causin, C. Marega, S. Schiavone, V.D. Guardia, A. Marigo, J. Anal. Appl. Pyrol. 75 (2006) 43.

[170] T. Takayasu, T. Ohshima, Japanese J. Forensic Tox. 18 (2000) 146.

[171] P. Maynard, K. Allwell, C. Roux, M. Dawson, D. Royds, Forensic Sci. Int. 124 (2001) 140.

[172] G.P. Campbell, A.L. Gordon, J. Forensic Sci. 52 (2007) 630.

[173] T. Ohshima, T. Kondo, Y. Sato, T. Takayasu, Forensic Sci. Int. 90 (1997) 131.

[174] T. Takayasu, T. Ohshima, T. Kondo, Leg. Med. 3 (2001) 157.

[175] T. Gözet, A.M. Önal, J. Hacaloglu, J. Macromol. Sci. A 44 (2007) 259.

[176] S. Sundarrajan, K.S.V. Srinivasan, Polym. Degrad. Stab. 91 (2006) 975.

[177] T. Uyar, E. Oztürk, K. Alyürük, J. Hacaloglu, J. Macromol. Sci. A 43 (2006) 1399.

49 [178] T. Uyar, E. Aslan, A.E. Tonelli, J. Hacaloglu, Polym. Degrad. Stab. 91 (2006) 1. 
Journal of Chromatography A 1186 (2008) 51-66

1 [179] E. Aslan, L. Toppare, J. Hacaloglu, Synthetic Met. 155 (2005) 191.

2 [180] G. Oguz, J. Hacaloglu, A.M. Onal, J. Macromol. Sci. A 42 (2005) 1387.

3 [181] R.P. Lattimer, J. Anal. Appl. Pyrol. 68-69 (2003) 3.

4 [182] Direct Pyrolysis/FT-IR: An alternative sampling system, CDSolutions, Oxford, PA, 2007.

5 [183] X. Kechang, L. Shengyu, Fenxi Huaxue 31 (2003) 501.

6 [184] A.R. Horrocks, D. Price, M. Akalin, Polym. Degrad. Stab. 52 (1996) 205. 
Journal of Chromatography A 1186 (2008) 51-66

\section{Figure legends}

Figure 1. Schematic diagram of a laser pyrolysis-GC system (from ref [11])

Figure 2. Pyrograms of blue paint (a) from the laser micropyrolysis GC/MS and (b) from the pyroprobe pyrolysis GC/MS (from ref [60])

Figure 3. Schematic diagram of an in-column pyrolysis-GC system (from ref [68])

Figure 4. Schematic diagram of a non-discriminating pyrolysis-GC system (from ref [68])

Figure 5. Schematic diagram of random scission mechanism (example of polyethylene) (from ref [73])

9 Figure 6. Schematic diagram of side group scission mechanism (example of polyvinyl chloride) (from 10 ref [73])

11 Figure 7. Schematic diagram of monomer reversion mechanism (example of polymethylmethacrylate) 12 (from ref [73])

13

14

15

16

\section{Figure 1}

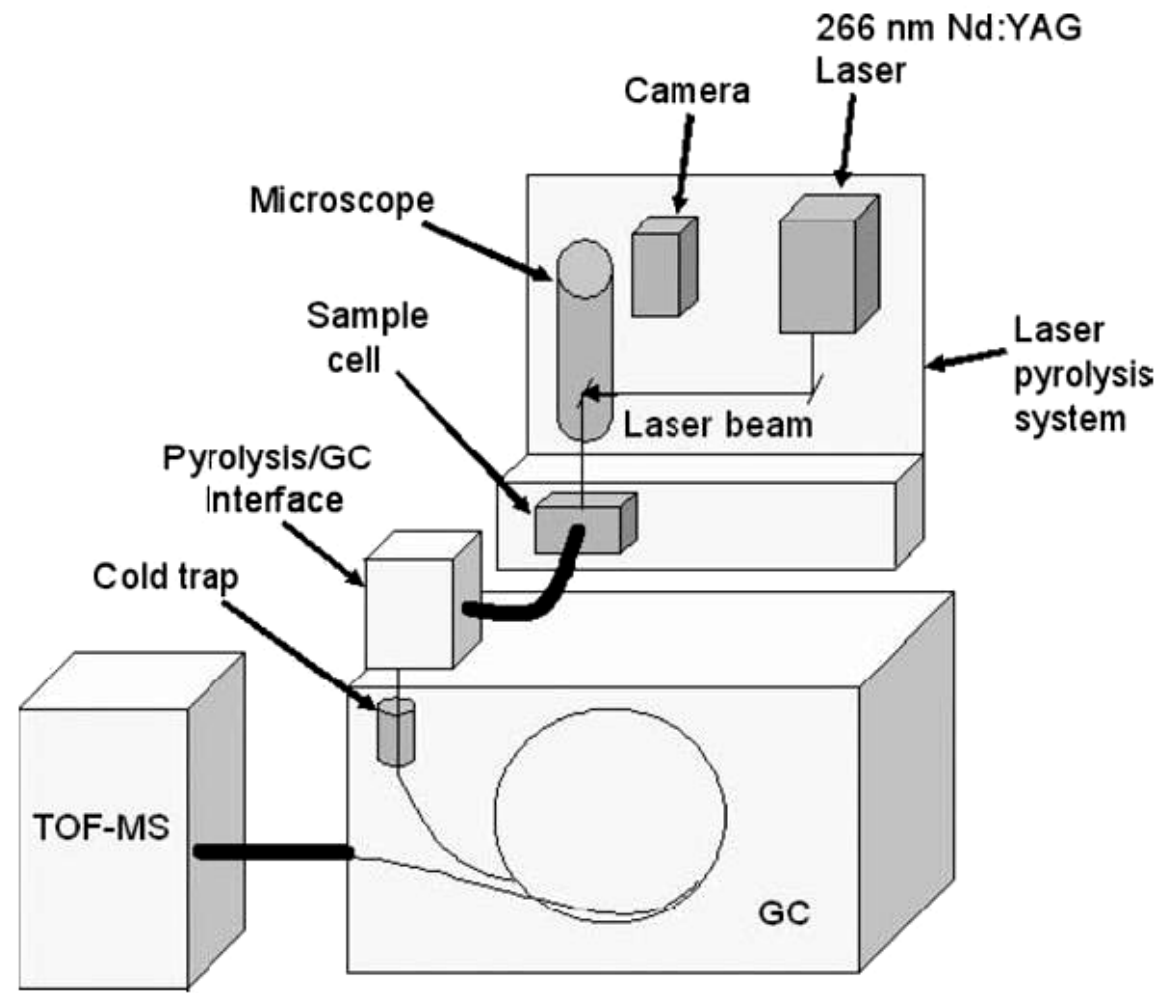


Journal of Chromatography A 1186 (2008) 51-66

1
2
3
4

Figure 2

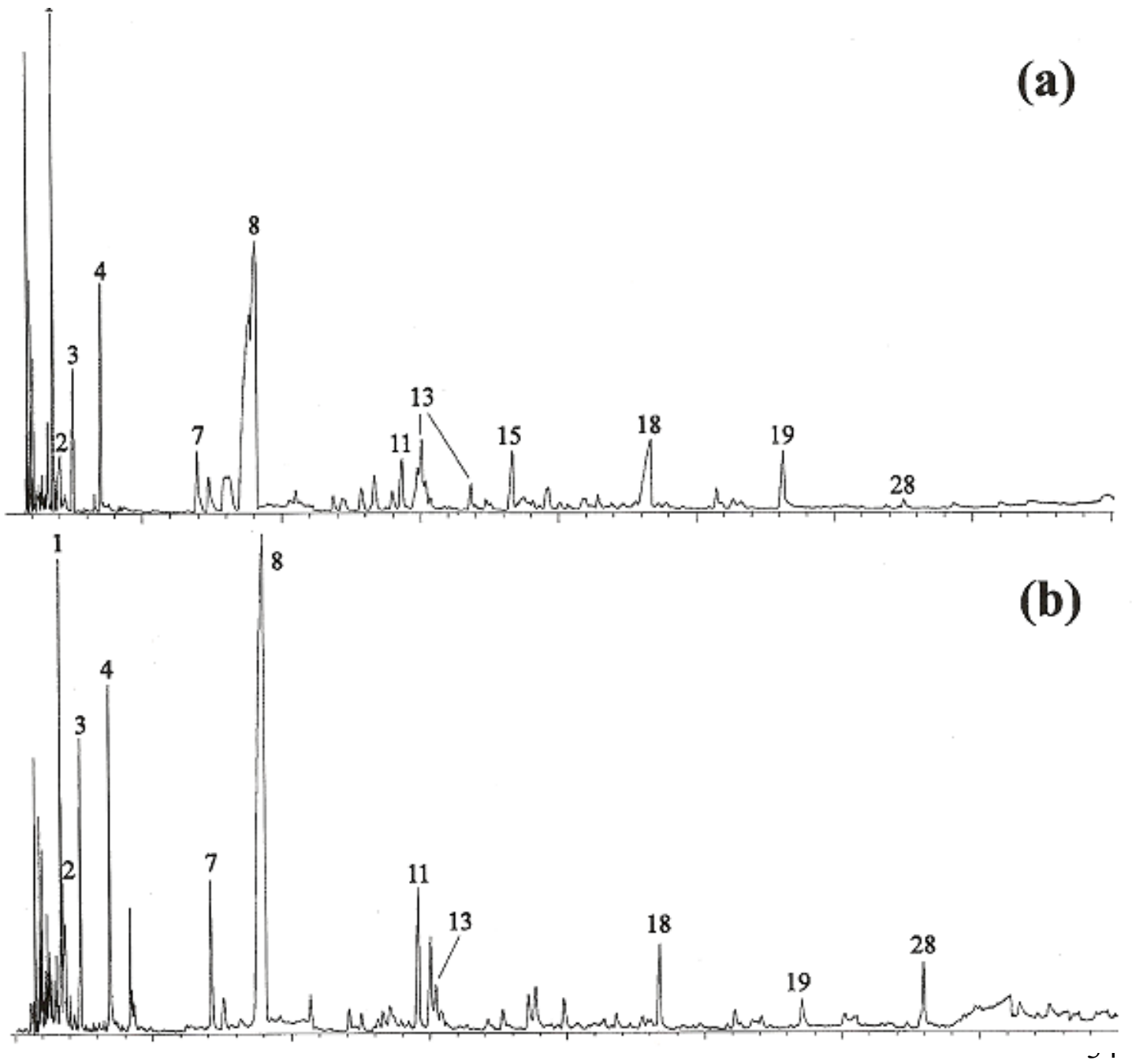

35

36

37

38

39

40

41

42

43

44

45

46

47

48

49 
Journal of Chromatography A 1186 (2008) 51-66

1

3

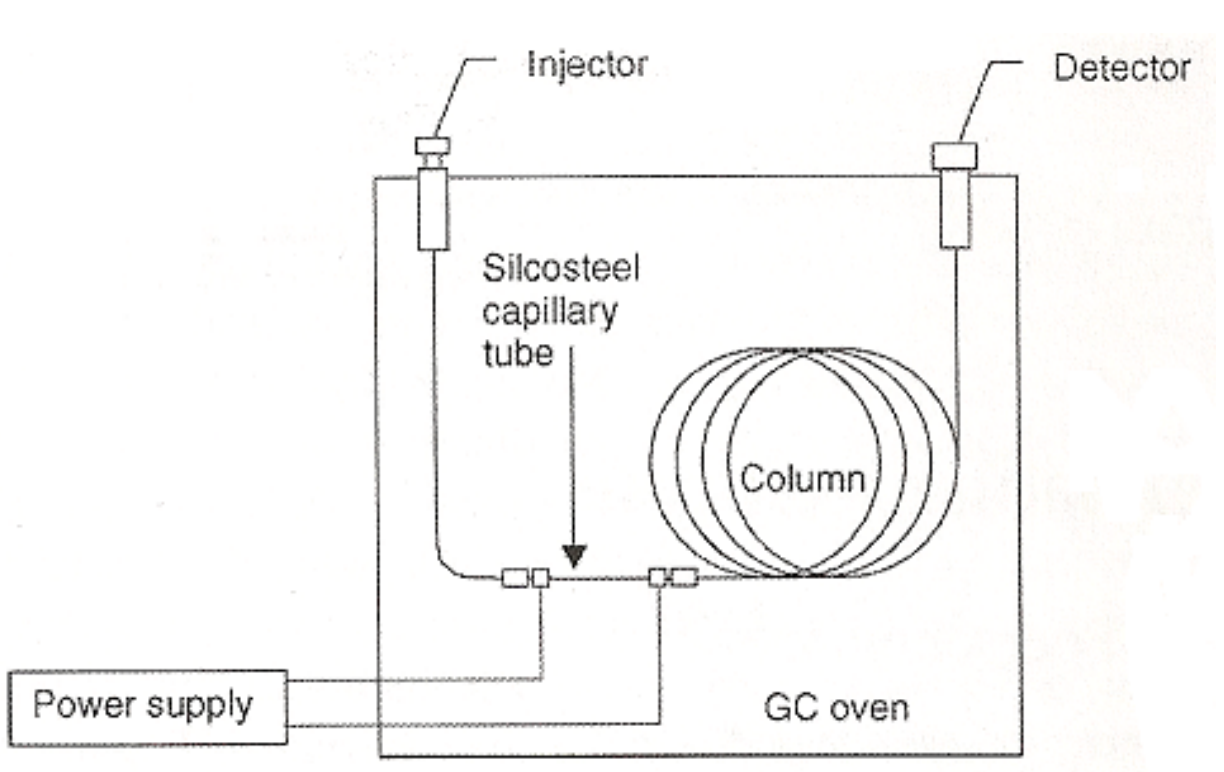

\section{Figure 3}

21

22

23

24

\section{Figure 4}

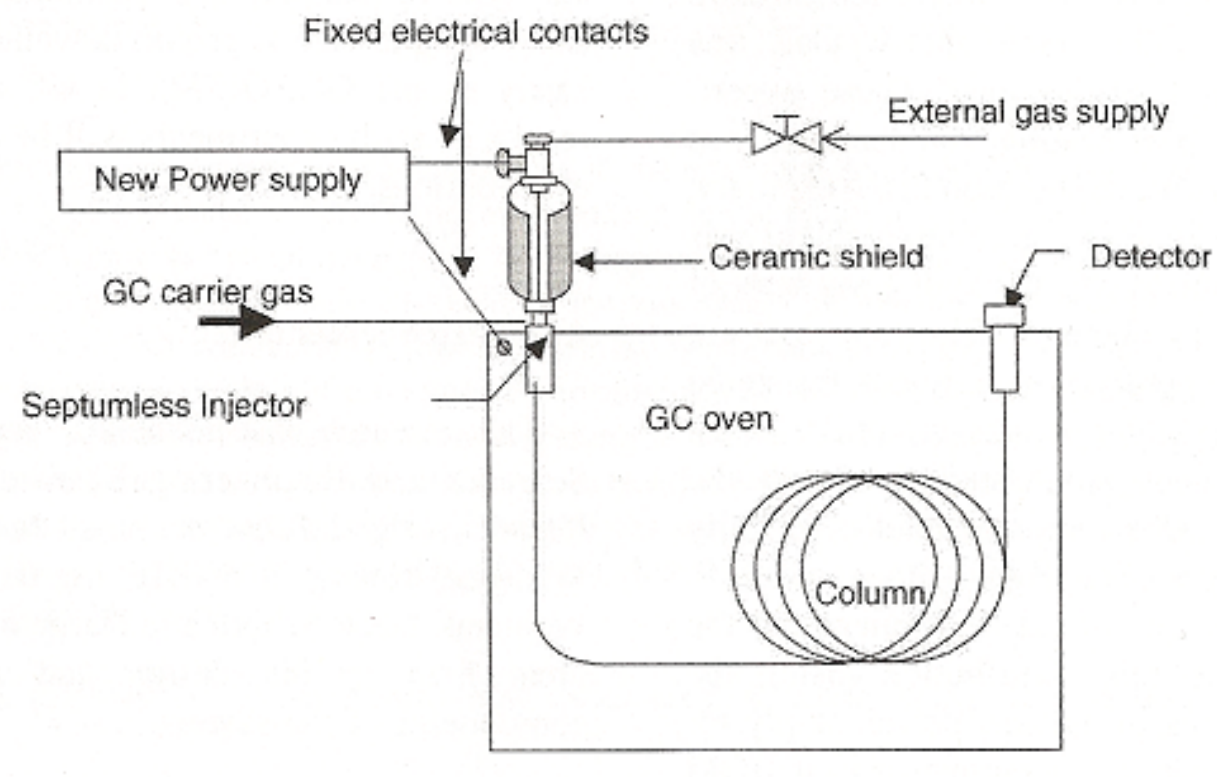


Journal of Chromatography A 1186 (2008) 51-66

Figure 5

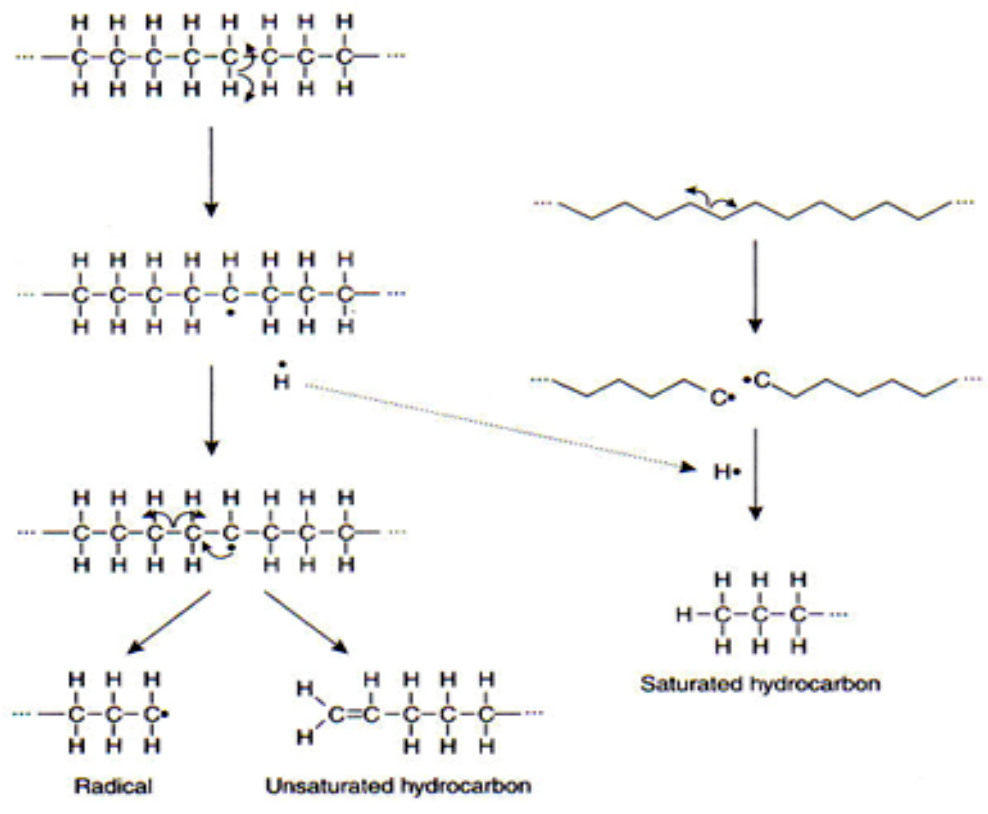

Figure 6

28

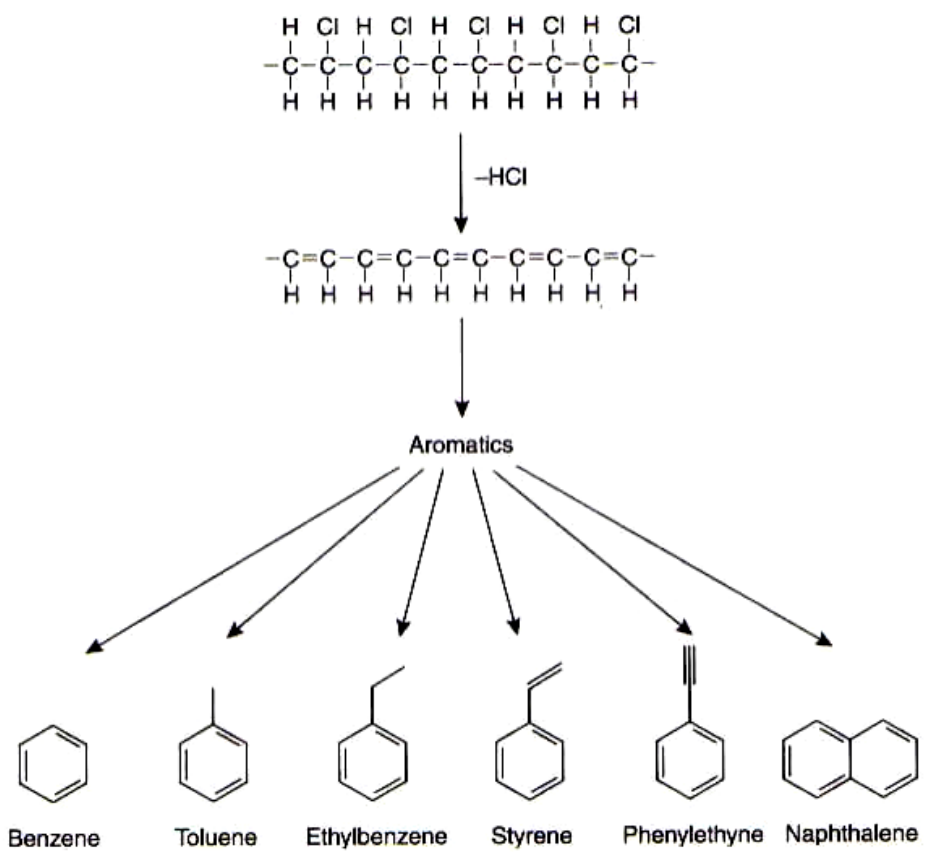


Journal of Chromatography A 1186 (2008) 51-66

1

2

3

Figure 7

1
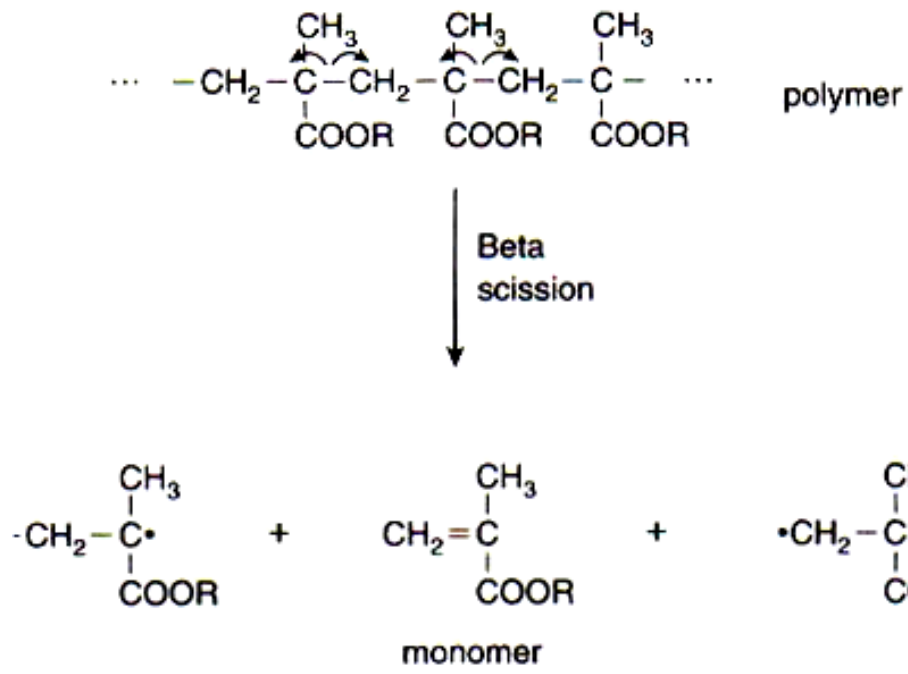<smiles>[CH2]C(C)(C)C(=O)O</smiles>

21

$\llcorner u$

22

23

24 